\section{The impact of universal newborn hearing screening}

\author{
Katherine Harrop-Griffiths
}

About 1 in 1000 children are born each year with hearing impairment sufficiently severe to compromise speech and language development and communication. There has been much work in recent years to reduce the age of diagnosis and intervention for these children. The paper by Pimperton et al, ${ }^{1}$ provides important evidence to support the observations of those working clinically with these children, that early identification and habilitation of significant hearing impairment in children pays dividends in terms of education. The cohort of children on whom this paper is based was identified by universal newborn hearing screening before the establishment of NHSP, the national newborn hearing screening programme. The same cohort was studied earlier at an average age of 7.9 years $^{2}$ when significant benefit in language development was shown in those diagnosed before 9 months of age compared with those identified when older than 9 months. The particular value of this paper is that it has looked at performance in the second decade as well as the first, and there is a paucity of work in this age group. Pimperton et al have highlighted the value of early diagnosis and intervention in establishing good language skills, which underpin later reading comprehension.

Management of deafness in children has seen a significant change in the last 15 years. Prior to newborn hearing screening, the average age of diagnosis of deafness severe enough to compromise speech and language development (moderate-to-profound deafness bilaterally) was 26 months, with hearing aid fitting at 32.2 months. ${ }^{3}$ Many of these children failed to acquire good speech and oral language. Amplification using hearing aids gave access to sound, but the late start meant that the critical period for good speech and language acquisition was passed. The average reading age of a deaf school leaver was said to be about 8 years, and career and educational opportunities were, as a consequence, limited.

The impetus for change came from the Joint Committee on Infant Hearing, a

Correspondence to Dr Katherine Harrop-Griffiths, UCLH, The Nuffield Hearing and Speech Centre, Royal National Throat, Nose and Ear Hospital, London, WC1X 8DA, UK; katherine.harrop-griffiths@uclh.nhs.uk multidisciplinary American group established in 1969, which first examined the evidence to support early screening and early intervention. Their latest supplement in 2013 presents current evidence. ${ }^{4}$ The majority of this research has come from the USA. Christine Yoshinaga-Itano, working for the Colorado Early Hearing Detection and Intervention programme, has monitored the identified children, providing excellent research data. A longitudinal study of deaf and hard of hearing children over a 7-year period identified age-appropriate speech and language development for children whose hearing loss was identified early and who had appropriate intervention, with the best results for those identified within the first 2 months of age. These children were shown to have better social-emotional development because of early and effective intervention. ${ }^{5}$ Her findings have been supported by others in the USA and also in this country as in this paper by Pimperton et al.

Examining the outcome of interventions for deaf children is difficult because of the many variables-degree of loss, additional needs, quality of intervention as well as the child's aptitude. A longitudinal study has benefit over a cross-sectional study in such a diverse group. It also provides evidence of sustained benefit. Its value in deaf children cannot be underestimated because screening costs and robust evidence of improved educational outcomes demonstrate value for money.

In England, funding for the NHSP from the National Screening Committee of the Department of Health was agreed in March 2000, and the project was established jointly with the Medical Research Council. The programme was rolled out across England over the next few years with $100 \%$ coverage (all children being offered screening) achieved by March 2006.

The beginning was a big change for many. It was not just the application of a two-level screen, which in itself was a challenge; it was what followed. Children were being referred from the screen at hours of age, and the specialist diagnostic tests needed were done to the level of expertise required in only a few centres.
The knowledge and skills needed to fit hearing aids to tiny babies were also in short supply. The teachers of the deaf providing peripatetic services were used to dealing with deaf toddlers and schoolchildren, but were now expected to cater for the hearing needs of small infants, only a few weeks of age. Only a few medics were adequately trained for the role ahead of them. In short, the learning curve was steep.

NHSP has not been just a screening programme, it had a much broader brief until recently-to ensure identified children were appropriately managed for the first 3 years of life. It has had precise standards of practice and performance with the child and the family at the centre, and it has provided an educational programme for involved professionals. A close working relationship with the National Deaf Children's Society resulted in the development of comprehensive information leaflets and support for parents. Through its robust quality assurance programme, NHSP ensured that every member of the multidisciplinary team was trained and involved in providing optimal care. Implementation of NHSP was like a military campaign, well thought out and, although not without its problems, successful. This success has ensured that many other countries have followed suite, and screening is offered across the UK as well as in other parts of the world.

There were two other important changes at the same time as the inception of NHSP. The start in 2000 coincided with MCHAS-modernising children's hearing aids - a project which introduced digital hearing aids into the UK for all children, with consistently high standards of fitting and maintenance of hearing aid care. At about the same time, there was an increasing confidence in, and acceptance of, cochlear implants for children. Early diagnosis following NHSP has reduced the age of implantation, affording the child the earliest possible access to good speech signals, with excellent results in speech and language development.

NHSP has also facilitated aetiological investigation by making this a part of the whole process and ensuring that medics have had the training to take this forward. In addition, part of NHSP has been the collection of robust and invaluable epidemiological data, but, unfortunately, the outcomes of screening have not yet been published. Although Public Health England, which has taken over hearing screening in England, now only covers screening, the pattern for subsequent care has been established and continues. 


\section{Editorials}

The children are the true beneficiaries of this exciting project. The effect of NHSP has been to significantly lower the age of confirmation of deafness. Figures show that the vast majority of congenitally deaf children have their hearing loss confirmed by 6 months of age with many identified within the first 4 weeks of life. Identification is the first step and ensures that habilitation is started within the first 6 months, with hearing aids being a part of that for many children. We are seeing the impact of early diagnosis in better speech and language skills and educational attainment. Pimperton et al's paper has shown exciting results with relatively early diagnosis (by 9 months). Hopefully, based on evidence from the USA, with lower ages of diagnosis, we may see even better reading competences for all deaf children in the future.

Competing interests None declared.

Provenance and peer review Commissioned; internally peer reviewed.

To cite Harrop-Griffiths K. Arch Dis Child 2016;101:1-2.

Received 20 March 2015

Revised 2 July 2015

Accepted 3 July 2015

Published Online First 7 September 2015

\section{(5) Linked}

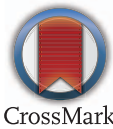

- http://dx.doi.org/10.1136/archdischild-2014-307516

Arch Dis Child 2016;101:1-2.

doi:10.1136/archdischild-2014-307867

\section{REFERENCES}

1 Pimperton $\mathrm{H}$, Blythe $\mathrm{H}$, Kreppner J, et al. The impact of universal newborn hearing screening on long-term literacy outcomes: a prospective cohort study. Arch Dis Child 2016;101:9-15.

2 Kennedy CB, McCann DC, Campbell MJ, et al. Language ability after early detection of permanent childhood hearing impairment. N Engl J Med 2006;354: 2131-41.

3 Fortnum H, Davis A. Epidemiology of permanent childhood hearing impairment in Trent Region, 19851993. Br J Audiol 1997;31:409-46.

4 Muse C, Harrison J, Yoshinaga-Itano C, et al. Joint Committee on Infant Hearing of the American Academy of Pediatrics. Supplement to the JCIH 2007 position statement: principles and guidelines for early intervention after confirmation that a child is deaf or hard of hearing. Pediatrics 2013; 131:e1324-49.

5 Yoshinage-Itano, C. From screening to early identification and intervention: discovering predictors to successful outcomes for children with significant hearing loss. I Deaf Stud Deaf Educ 2003:8:11-30. 